\title{
The Preventive Effects of Different Doses of Glucomannan on Experimental Aflatoxicosis in Japanese Quails
}

\section{mAuthor(s)}

\section{Yavuz O' \\ Özdemir Ö \\ Ortatatli M \\ Atalay B"II \\ Hatipoglu F" \\ Terzi F"}

Aksaray University, Faculty of Veterinary Medicine, Department of Pathology, Aksaray/TURKEY

" Selçuk University, Faculty of Veterinary Medicine, Department of Pathology, Konya/ TURKEY

III Batman University, Vocational High School of Health Services, Batman/TURKEY

\section{a Mail Address}

Corresponding author e-mail address Yavuz Orhan

Aksaray University, Faculty of Veterinary Medicine, Department of Pathology, 68100 PBX /Aksaray/TURKEY.

Tel: $\quad+903822882940$

Email: vetorhanyavuz@gmail.com

\section{-Keywords}

Aflatoxin, glucomannan, histopathology، quail.

\section{ABSTRACT}

This experimental study was performed to investigate whether there is a protective effect of different doses of Glucomannan using against aflatoxicosis in Japanese quail, and pathological changes and relative organ weights were compared.

In the experiment, 60 one-day old male Japanese quails were used as divided into six different groups. Experimental groups were designated as Control(C), aflatoxin(A), glucomannan(GM), 2-fold dose of glucomannan(2GM), aflatoxin+glucomannan(A+GM) and aflatoxin+2-fold dose of glucomannan $(A+2 G M)$. While control group quails fed the standard ration as ad libitum, other groups were fed with the administrations additionally to standard diet respectively; $2 \mathrm{mg} / \mathrm{kg}$ of aflatoxin to group A, $1 \mathrm{~g} / \mathrm{kg}$ of glucomannan to group $\mathrm{GM}, 2 \mathrm{~g} / \mathrm{kg}$ of glucomannan to group $2 \mathrm{GM}, 2 \mathrm{mg} / \mathrm{kg}$ of aflatoxin and $1 \mathrm{~g} / \mathrm{kg}$ glucomannan to group $\mathrm{A}+\mathrm{GM}, 2 \mathrm{mg} / \mathrm{kg}$ of aflatoxin and $2 \mathrm{~g} /$ $\mathrm{kg}$ glucomannan to group $\mathrm{A}+2 \mathrm{GM}$. All quails were euthanized at day 21 of the study and organs, (liver, spleen, kidney, thymus and bursa of Fabricius) were removed, weighed and subjected to routine histopathological procedures.

Although any important macroscopic changes were not observed in the C, GM and 2GM groups, significant pathological changes were found in the groups of $A, A+G M$ and $A+2 G M$. In the $A+G M$ group, the partial reduction in the severity of microscopic lesions were seen in liver, bursa of Fabricius, thymus and spleen, however a significant reduction in severity of lesions was noticed in A+2GM group.

As a result of the study, $2 \mathrm{~g} / \mathrm{kg}$ of glucomannan has been found pathologically to be more effective than $1 \mathrm{~g} / \mathrm{kg}$ glucomannan in terms of the protection against aflatoxicosis by giving orally.

\section{INTRODUCTION}

Aflatoxins (AF) are toxic metabolites produced by fungi, such as Aspergillus flavus and Aspergillus parasiticus, and are considered to be the most harmful mycotoxins as they are highly toxic to animals and humans (Kaya, 1989; Hoerr, 2003). There are six different kinds of aflatoxins: B1, B2, G1, G2, M1, M2. Aflatoxin B1 (AFB1) is accepted as the most harmful, as well as most common metabolite in feeds and foods (Hatch, 1988). Aflatoxicosis in quails has been thoroughly investigated by many scientists, and was shown to be as economically important for quail production as for that of other poultry (Parlat et al., 2001; Oliveira et al., 2002; Oguz \& Parlat, 2004; Sehu et al., 2005; Cengiz et al., 2008). Aflatoxins impair performance parameters, such as feed conversion ratio, body weight gain, egg production, and growth rate in all poultry species (Erdeger, 2002). Similarly, it has been reported that AF have adverse effects on the growth performance and health 
Yavuz O, Özdemir Ö, Ortatatli M, Atalay B, Hatipoglu F, Terzi F
The Preventive Effects of Different Doses of Glucomannan on Experimental Aflatoxicosis in Japanese Quails of quails, and as well as carcinogenic and mutagenic effects (Parlat et al., 2001).

When orally ingested with water and feed, AF are absorbed in the digestive tract and are bound to serum albumin. Circulating AF are largely metabolized in the liver. Part of the AF bind to macromolecules, such as endoplasmic steroids and enzymes in the hepatocytes, whereas the remaining part is converted into fat and water - soluble metabolites. AF itself is actually harmless, but its metabolization in the liver through cytochrome P-450, produces epoxide derivatives. After this stage, $A F$ acquires toxic properties and plays a role in the inhibition of DNA, RNA, and protein synthesis in liver. In addition, its binding to several macromolecules causes cytotoxic, carcinogenic and teratogenic effects (Abdel-Wahhab \& Aly, 2005). In addition, acute and chronic poisoning, as well as mutagenic and immunosuppressive effects have been reported (Kiran et al., 1998; Sur \& Celik, 2003).

Duck and turkeys are the most sensitive poultry species to aflatoxicosis, quails are moderately susceptible, whereas chickens are considered the most resistant. It has been reported that pheasants, geese, and chickens are more resistant than ducks and turkeys. Bobwite quails are more susceptible than Japanese quails (Ruff et al., 1992). The most obvious macroscopic findings related to acute and chronic aflatoxicosis are observed in the liver. Lesions can also be observed in other organs, such as the kidneys, spleen and bursa of Fabricius (Diaz et al., 2008).

As in other poultry, AF can cause depression, anorexia, icterus, hemorrhages, and death in quails (Oliveira et al., 2002). The most obvious macroscopic findings are observed in the liver in acute and chronic aflatoxicosis. In addition, lesions are found in other organs such as the kidney, spleen, and bursa of Fabricius (Sawhney et al., 1973; Ortatatli et al., 2005). At gross examination, the liver is pale and enlarged. The main histopathological findings are oil vacuoles in the hepatocytes, hydropic degeneration, necrosis, and bile duct proliferation (Ortatatli \& Oguz, 2001). The kidney and spleen may be enlarged, and their surfaces may present petechial hemorrhages (Bilgic \& Yesildere, 1992). Tubular degeneration and capillary hyperemia are commonly observed in the kidneys, and lymphoid-cell depletion and necrosis in the spleen. The bursa of Fabricius may present lymphoid-cell depletion and intrafollicular cysts (Ortatatli et al., 2002).

Glucomannans (GM) are extracted from the cell wall of the live yeast Saccharomyces cerevisiae, and were used to prevent the absorption of mycotoxins in the early 1990s (Stanley et al., 1993). It was demonstrated that GM present a strong capacity to bind AF in vivo and in vitro when added to poultry diets (Bintvihok et al., 2002; Karaman et al., 2005; Oguz, 2011; Azizpour \& Moghadam, 2015). The positive effect of GM on oxidative stress parameters was also shown in quails (Atalay, 2010).

The present study investigated if the dietary addition of different doses of GM were effective for the protection of Japanese quails against aflatoxicosis. For this purpose, relative organ weights (liver, kidney, spleen, bursa of Fabricius and thymus) were calculated, and pathological changes in the organs were compared.

\section{MATERIALS AND METHODS}

\section{Birds and treatments}

Sixty one-day old male Japanese quails (Coturnix coturnix japonica) were evaluated. The quails were obtained from Selçuk University, Faculty of Agriculture, Poultry Unit. The quails were housed in electricallyheated cages, at a density of 30 birds per cage, and provided with continuous lighting. A commercial basal diet $(65 \%$ corn, 32\% soybean meal, 3\% vitaminmineral premix), supplemented with amino acids, minerals, and vitamins at the levels recommended by the National Research Council (NRC, 1994), was fed. Before being supplied, the basal diet was proven to be clear from any detectable levels of residual AF (Howell \& Taylor, 1981) at a detection limit of $1 \mu \mathrm{g} / \mathrm{kg}$ feed, using thin-layer chromatography (TLC) at 95\% recovery rate. This basal diet was contaminated or not with aflatoxin and supplemented with a glucomannan at 1 or $2 \mathrm{~g} / \mathrm{kg}$ of diet, according to the treatments: control (C), basal diet; aflatoxin (A), $2 \mathrm{mg}$ aflatoxin $/ \mathrm{kg}$ basal diet; glucomannan (GM), $1 \mathrm{~g}$ glucomannan/kg basal diet; two-fold dose of glucomannan (2GM), $2 \mathrm{~g}$ glucomannan $/ \mathrm{kg}$ basal diet;aflatoxin + glucomannan $(A+G M)$, basal diet containing $2 \mathrm{mg}$ aflatoxin/ $/ \mathrm{kg}$ plus $1 \mathrm{~g}$ glucomannan/kg; and aflatoxin + two-fold dose of glucomannan $(A+2 G M)$, basal diet containing $2 \mathrm{mg}$ aflatoxin/kg plus $2 \mathrm{~g}$ glucomannan $/ \mathrm{kg}$. The Japanese quails were equally divided into the six treatments with 10 birds each, and were fed the experimental diets from one to 21 days of age.

\section{Aflatoxin and glucomannan analyses}

The AF content in rice powder was analyzed and measured on thin layer chromatography-fluorometric densitometer (TLC) (Camag II, Basel, Switzerland). The AF was produced from a culture of Aspergillus parasiticus NRRL 2999 (USDA, Agricultural Research 
Service, Peoria, IL) via rice fermentation by the method of Shotwell et al. (1966), with minor modifications by Demet et al. (1995) and Oguz (1997). Briefly, $100 \mathrm{~g}$ of sterile polished rice were inoculated with 1 $\mathrm{mL}$ of resuspended spores $(1.5 \times 106$ spores $/ \mathrm{mL})$ of Aspergillus parasiticus NRRL 2999, placed an incubator at $28^{\circ} \mathrm{C}$, and fermented for five days. AF was extracted as follows. Briefly, $10 \mathrm{~g}$ of fermented rice powder were accurately weighed and dispersed in $100 \mathrm{~mL}$ of distilled water and fixed for five minutes. Then, $100 \mathrm{~mL}$ of chloroform were added to the solution and blended for 15 minutes at $3000 \mathrm{rpm}$ in a centrifuge. The chloroform phase was taken into a separating funnel already containing $15 \mathrm{~g}$ of anhydrous sodium sulfate. The collected chloroform evaporated to dryness in a rotary evaporator. Dried sample extracts were individually $(2,5,10 \mu \mathrm{L})$ applied on the TLC plates, which were developed in an unlined tank containing $20 \mathrm{~mL}$ of chloroform:xylene:acetone $(7: 2: 1 ; \mathrm{v} / \mathrm{v})$ and observed under UV light (365 $\mathrm{nm}$ wavelengths and 425 emission). The AF in the rice powder consisted of 82.3\% AFB1, 2.06\% AFB2, 7.68\% AFG1, and 7.96\% AFG2 based on total AF in the ground rice powder (detection limit of aflatoxin: $1 \mu \mathrm{g}$ aflatoxin $/ \mathrm{kg}$ rice powder. Recovery of the extraction method: 92\%). The rice powder was incorporated into the basal diet in order to provide the desired amount of $2 \mathrm{mg} \mathrm{AF} / \mathrm{kg}$ feed.

Esterified glucomannan (Mycosorb $®$, Alltech Inc. KY., USA) was used as binding agent of AF.

\section{Pathological Examination}

All quails in each group on day 21 of the study were weighed, euthanized by decapitation, and necropsied. The liver, kidneys, spleen, thymus and bursa of Fabricius were collected and weighed on a precision scale to calculate relative organ weight as a percentage of live weight.

The collected organs were fixed in 10\% formalin solution, dehydrated in graded alcohol series, cleared in xylene, and embedded in paraffin blocks. Tissues were cut in 5- $\mu \mathrm{m}$ thick sections using a microtome, mounted on slides, stained with hematoxylin and eosin (Luna, 1968), and examined under a light microscope.

In histopathological examination, liver degenerative changes were scored according to the method described by Ortatatli et al. (2005). Mild hepatocellular swellings due to hydropic and fatty degeneration only in centrilobular areas were scored as 1 (Mild); evident hepatocellular swelling in the centrilobular and the intermediate areas of lobules, were scored as 2 (Intermediate); and severe hepatocellular swellings extending to the whole lobules were scored as 3 (Severe). Lymphoid depletion in the bursa of Fabricius and spleen, cortical atrophy in the thymus, and tubular degeneration in the kidneywere evaluated by histopathology.

\section{Statistical Analysis}

The Kruskal-Wallis test was applied to compare the gross and histopathological findings among treatments. Relative organ weight differences were compared by Duncan's multiple range test (IBM ${ }^{\circledR}$ SPSS $^{\circledR}$ Statistics Version 22). Statements of statistical significance are based on a $p$ value of $<0.05$.

\section{RESULTS}

Pathological findings of liver, spleen, kidney, thymus and bursa of Fabricius are summarized in Table 1.

Table 1 - Distribution of the lesions in the organs from day 1 to 21 trial period.

\begin{tabular}{|c|c|c|c|c|c|c|}
\hline Lesions/Changes & $\begin{array}{c}\text { Control } \\
\text { Normal Diet }\end{array}$ & $\begin{array}{c}\mathrm{A} \\
2 \mathrm{mg} / \mathrm{kg} \text { of } \mathrm{AF}\end{array}$ & $\begin{array}{c}\mathrm{GM} \\
1 \mathrm{~g} / \mathrm{kg} \text { of } \mathrm{GM}\end{array}$ & $\begin{array}{c}A+G M \\
2 \mathrm{mg} / \mathrm{kg} \text { of } A F+ \\
1 \mathrm{~g} / \mathrm{kg} \text { of } \mathrm{GM}\end{array}$ & $\begin{array}{c}2 \mathrm{GM} \\
2 \mathrm{~g} / \mathrm{kg} \text { of } \mathrm{GM}\end{array}$ & $\begin{array}{c}\mathrm{A}+2 \mathrm{GM} \\
2 \mathrm{mg} / \mathrm{kg} \text { of } \mathrm{AF}+ \\
2 \mathrm{~g} / \mathrm{kg} \text { of } \mathrm{GM}\end{array}$ \\
\hline $\begin{array}{l}\text { Gross findings on liver } \\
\text { (Enlargement and paleness) }\end{array}$ & $0 / 10^{b}$ & $6 / 10^{a}$ & $1 / 10^{\mathrm{ab}}$ & $4 / 10^{\mathrm{ab}}$ & $1 / 10^{\mathrm{ab}}$ & $1 / 10^{\mathrm{ab}}$ \\
\hline Hydropic and/or fatty changes in hepatocytes & $1 / 10^{b}$ & $9 / 10^{a}$ & $4 / 10^{b}$ & $5 / 10^{\mathrm{ab}}$ & $3 / 10^{b}$ & $5 / 10^{\mathrm{ab}}$ \\
\hline Mild & 1 & 1 & 3 & 1 & 3 & 3 \\
\hline Moderate & 0 & 2 & 1 & 0 & 0 & 2 \\
\hline Severe & 0 & 6 & 0 & 4 & 0 & 0 \\
\hline Bile duct proliferation & $0 / 10^{b}$ & $6 / 10^{a}$ & $2 / 10^{a b}$ & $6 / 10^{a}$ & $2 / 10^{a b}$ & $2 / 10^{\mathrm{ab}}$ \\
\hline Lymphoid depletion (Spleen) & $1 / 10^{\mathrm{ab}}$ & $5 / 10^{a}$ & $2 / 10^{a b}$ & $4 / 10^{a b}$ & $0 / 10^{b}$ & $0 / 10^{b}$ \\
\hline Lymphoid depletion (Bursa of Fabricius) & $4 / 10^{\mathrm{ab}}$ & $9 / 10^{a}$ & $5 / 10^{\mathrm{ab}}$ & $7 / 10^{\mathrm{ab}}$ & $2 / 10^{b}$ & $2 / 10^{b}$ \\
\hline Cortical atrophy (Thymus) & $1 / 10^{b}$ & $8 / 10^{a}$ & $3 / 10^{a b}$ & $6 / 10^{\mathrm{ab}}$ & $1 / 10^{b}$ & $1 / 10^{b}$ \\
\hline Tubular degeneration (Kidney) & $1 / 10^{b}$ & $9 / 10^{a}$ & $1 / 10^{b}$ & $9 / 10^{a}$ & $0 / 10^{b}$ & $1 / 10^{b}$ \\
\hline
\end{tabular}

a-b Values within rows with no common superscripts are significantly different, according to Kruskal Wallis test.

Control: Normal diet; A: Aflatoxin Group, 2mg/kg aflatoxin; GM: Glucomannan Group, 1g/kg glucomannan; A+GM: Aflatoxin + Glucomannan Group, 2 mg/kg aflatoxin + 1g/kg glucomannan; 2GM: 2-fold dose of Glucomannan Group, 2g/kg glucomannan; A+2GM: Aflatoxin + 2-fold dose of Glucomannan Group, 2 mg/kg aflatoxin + 2g/kg glucomannan. 
Yavuz O, Özdemir Ö, Ortatatli M, Atalay B, Hatipoglu F, Terzi F

\section{The Preventive Effects of Different Doses of Glucomannan on Experimental Aflatoxicosis in Japanese Quails}

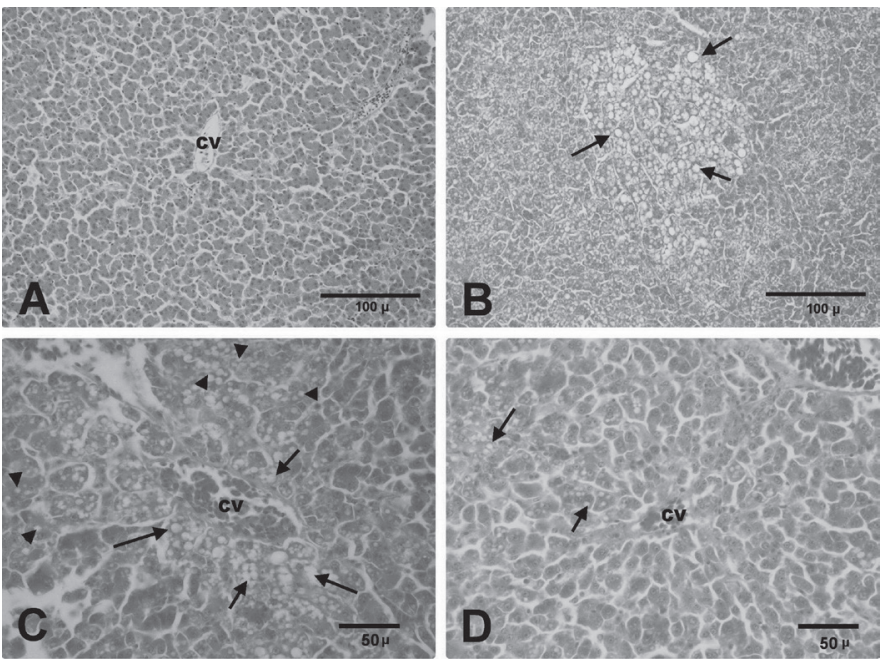

Figure 2 - Histopathological findings on the liver. A. Control group. Central vein (CV) and normal hepatocytes. B. Aflatoxin Group (2mg/kg of AF). Severe fatty changes and hydropic degenerations on the hepatocytes (arrows). C. A+GM Group (2mg/kg of AF + $1 \mathrm{~g} / \mathrm{kg}$ of GM). Centro-lobular (arrows) and intermediar (arrow heads) fatty changes on the hepatocytes around of the central vein (CV). D. A+2GM Group ( $2 \mathrm{mg} / \mathrm{kg}$ of AF $+2 \mathrm{~g} /$ $\mathrm{kg}$ of GM). A small number of hydropic degenerations (arrows) around of the central vein $(\mathrm{CV})$.

and $3 / 10$, respectively), and groups $2 \mathrm{GM}$ and $A+2 G M$, the lowest, with only $1 / 10$ birds each.

No kidney necrosis and hemorrhages were found. Degenerative changes in renal tubular epithelia were observed in a higher number of birds of groups $A$ and $A+G M$ (9/10 each) compared with the other groups (1/10 in GM and $A+2 G M$ and none in the 2GM group), as shown in Table 1.

The relative organ weights of liver, kidney, spleen, bursa of Fabricius, and thymus are presented in Table 2. There were no differences in the relative weights of the kidneys and spleen among treatments. Birds of group A presented the heaviest livers and the $A+G M$ and $2 \mathrm{GM}$ birds, the lightest, whereas the relative liver weights of the $G M$ and the $A+G M$ birds had intermediate values. The bursa of $A+G M$ birds was lighter than those of the 2GM birds, whereas the other groups presented intermediate values. The highest and the lowest relative thymus weight were observed in group $A+2 G M$ and $A+G M$, respectively, whereas the remaining groups weren't statistically different from each other.

\section{DISCUSSION}

Macroscopic and microscopic examinations are very effective methods to demonstrate the pathological findings of aflatoxicosis (Bintvihok et al., 2002). In particular, it was reported that the liver, kidney, spleen, thymus, and bursa of Fabricius are the target organs of aflatoxicosis (Ortatatli et al., 2005). As mentioned 
Table 2 - Effects of glucomannan on relative organ weights for quails fed on diet containing total aflatoxin between $1-21$ days age.

\begin{tabular}{lccccc}
\hline & \multicolumn{5}{c}{ Relative Organ Weights (organ weight / 100 gr live body weight) } \\
\hline Groups & Liver & Kidney & Spleen & B.Fabricius & Thymus \\
\hline Control & $3.660^{\mathrm{a}} \pm 0.151$ & $0.586^{\mathrm{a}} \pm 0.029$ & $0.079^{\mathrm{a}} \pm 0.007$ & $0.157^{\mathrm{c}} \pm 0.017$ & $0.357^{\mathrm{c}} \pm 0.041$ \\
$\mathrm{~A}$ & $4.552^{\mathrm{b}} \pm 0.195$ & $0.635^{\mathrm{a}} \pm 0.041$ & $0.093^{\mathrm{a}} \pm 0.013$ & $0.108^{\mathrm{ab}} \pm 0.010$ & $0.233^{\mathrm{ab}} \pm 0.020$ \\
$\mathrm{GM}$ & $3.292^{\mathrm{a}} \pm 0.111$ & $0.528^{\mathrm{a}} \pm 0.033$ & $0.067^{\mathrm{a}} \pm 0.006$ & $0.132^{\mathrm{abc}} \pm 0.018$ & $0.313^{\mathrm{bc}} \pm 0.025$ \\
$\mathrm{~A}+\mathrm{GM}$ & $3.929^{\mathrm{ab}} \pm 0.286$ & $0.544^{\mathrm{a}} \pm 0.046$ & $0.072^{\mathrm{a}} \pm 0.011$ & $0.089^{\mathrm{a}} \pm 0.015$ & $0.182^{\mathrm{a}} \pm 0.014$ \\
$2 \mathrm{GM}$ & $4.041^{\mathrm{ab}} \pm 0.273$ & $0.601^{\mathrm{a}} \pm 0.039$ & $0.066^{\mathrm{a}} \pm 0.006$ & $0.144^{\mathrm{bc}} \pm 0.010$ & $0.250^{\mathrm{ab}} \pm 0.022$ \\
$\mathrm{~A}+2 \mathrm{GM}$ & $3.716^{\mathrm{a}} \pm 0.330$ & $0.573^{\mathrm{a}} \pm 0.022$ & $0.084^{\mathrm{a}} \pm 0.008$ & $0.132^{\mathrm{abc}} \pm 0.013$ & $0.371^{\mathrm{c}} \pm 0.035$ \\
\hline
\end{tabular}

Values represent the mean \pm SEM of six groups of 10 quails each per treatment.

a-c Values within column with no common superscripts are significantly different ( $p$ value<0.05), according to Duncan's Multiple Range Test

Control: Normal diet; A: Aflatoxin Group, 2mg/kg aflatoxin; GM: Glucomannan Group, 1g/kg glucomannan; A+GM: Aflatoxin + Glucomannan Group, 2 mg/kg aflatoxin + 1g/kg glucomannan; 2GM: 2-fold dose of Glucomannan Group, 2g/kg glucomannan; A+2GM: Aflatoxin + 2-fold dose of Glucomannan Group, 2 mg/kg aflatoxin + 2g/kg glucomannan.

in previous studies, aflatoxicosis histopathological findings are directly proportional to the exposure time and intensity of the toxin (Magnoli et al., 2012). In 21 day trial period of the present study, the toxic effects of AF and the protective effects of GM were histologically demonstrated.

Liver paleness and hepatomegaly are important indicators of aflatoxicosis (Hoerr, 2003; Ortatatli et al., 2005). While no gross changes were observed in the Control, GM and 2GM groups, the livers of the birds of the $A$ and $A+G M$ groups were very swollen and pale. In contrast, the severity of liver lesions was mild in the A+2GM group, whereas $6 / 10$ and $4 / 10$ birds of the $A$ and $A+G M$ groups presented severe lesions. The difference between these groups ( $A$ and $A+2 G M$ ) was statistically significant. The macroscopic liver changes observed in the present study are consistent with previously reported studies (Sawhney et al., 1973; Ortatatli \& Oguz, 2001; Oliveira et al., 2002; Ortatatli et al., 2005; Citil et al., 2007; Magnoli et al., 2012; Ibrahim, 2013).

The most common finding in aflatoxicosisis fatty and hydropic degeneration of the liver, as observed by microscopic examination (Sawhney et al., 1973; Bryden \& Cumming, 1980; Ortatatli \& Oguz, 2001; Oliveira et al., 2002; Karaman et al., 2005; Ortatatli et al., 2005; Attia et al., 2016). No severe lesions were observed in the Control, GM, 2GM, and A+2GM birds. Severe hydropic and fatty degeneration were present in the livers of group A. In addition, marked diffuse fatty changes, bile duct proliferation, and periportal fibrosis were detected in the portal areas of those birds. In a similar study in broiler chickens, broilers were fed $2 \mathrm{mg}$ aflatoxins $/ \mathrm{kg}$ diet+ $0.5 \mathrm{~g}$ or $1 \mathrm{~g}$ glucomannan / $\mathrm{kg}$ diet and reported very mild liver lesions with the addition of glucomannan (Karaman et al., 2005). In the present study, the severity of the hydropic and fatty degeneration was reduced when broilers fed the AFcontaminated diet received $2 \mathrm{~g}$ of GM compared with $1 \mathrm{~g}$.

Lymphoid organs, such as the spleen, bursa of Fabricius, and thymus are primarily affected by aflatoxicosis (Ortatatli et al., 2005). Pathological changes in the lymphoid organs caused by aflatoxicosis were microscopically shown in the present study. Lymphoid cell depletion in bursa of Fabricius, thymus and spleen were more frequently observed in groups $A$ and $A+G M$. Necrosis of the germinal centers of the lymphoid follicles and rarely intrafollicular cysts were found in these groups. Cortical atrophy of thymus and necrosis and spleen lymphoid tissue depletion were evident. The highest frequency of birds with lymphoid tissue depletion both in the spleen and the bursa were determined in group $A$, whereas the lowest in groups $2 \mathrm{GM}$ and $\mathrm{A}+2 \mathrm{GM}$. The lesions of group $\mathrm{A}+2 \mathrm{GM}$ were mild and found in a limited number of birds. The number of birds with lymphoid lesions in the control, GM and 2GM groups was not statistically different from the $A$ and the $A+2 G M$ groups.

Due to the short duration of this study, only degenerative changes were observed in the kidneys, and not necrosis and intertubular hemorrhages commonly observed with the chronic intoxication with aflatoxin (Bilgic \& Yesildere, 1992; Valchev et al., 2014).

Kubena et al. (1990) observed that changes in liver weight are a more sensitive indicator of aflatoxicosis compared with the weight of other organs, such as kidneys, spleen, and pancreas. In our study, relative liver weight was higher in group A compared with the Control, GM and $A+2 G M$ groups, whereas the groups $2 G M$ and $A+G M$ presented intermediate values. The heavier livers of the birds fed only aflatoxin may be due to the histopathological fatty changes in the 
Yavuz O, Özdemir Ö, Ortatatli M, Atalay B, Hatipoglu F, Terzi F

\section{The Preventive Effects of Different Doses of Glucomannan on Experimental Aflatoxicosis in Japanese Quails}

during chronic aflatoxicosis. Kafkas Üniversitesi Veteriner Fakültesi Dergisi 2007;13:75-85.

Demet O, Oguz H, Celik I, Nizamlioglu F. Pirinçte aflatoksin üretilmesi. Eurasian Journal of Veterinary Science 1995;11:19-23.

Diaz GJ, Calabrese E, Blain R. Aflatoxicosis in chickens (gallus gallus). an example of hormesis. Poultry Science 2008;87(4):727-732.

Eraslan G, Liman BC, Guclu BK, Atasever A, Koc AN, Beyaz L. Evaluation of aflatoxin toxicity in japanese quails given various doses of hydrated sodium calcium aluminosilicate. Bulletin of the Veterinary Institute in Pulawy 2004;48:511-517.

Erdeger J. Aflatoksikozis. Kanatlı hayvan hastalıkları. Ankara: Medisan Press; 2002

Girish CK, Devegowda G. Efficacy of glucomannan-containing yeast product (mycosorb) and hydrated sodium calcium aluminosilicate in preventing the Individual and combined toxicity of aflatoxin and t-2 toxin in commercial broilers. Asian-Australasian Journal of Animal Sciences 2006;19:877 - 883.

Hatch RC. Veterinary pharmacology and therapeutics. 6th ed. Ames: lowa State University Press; 1988

Hoerr JF. Mycotoxicoses. In: Calnek BW, et al. Diseases of poultry. 11th ed. Ames: lowa State University Press; 2003.

Howell MV, Taylor PW. Determination of aflatoxins, ochratoxin a, and zearalenone in mixed feeds, with detection by thin layer chromatography or high performance liquid chromatography. Journal Association of Official Analytical Chemists 1981;64:1356-1363.

Ibrahim QQ. Histopathological study of quails liver experimentally induced by aflatoxin. Basrah Journal of Veterınary Research 2013;12:116-127.

Karaman M, Basmacioglu $H$, Ortatatli $M$, Oguz $H$. Evaluation of the detoxifying effect of yeast glucomannan on aflatoxicosis in broilers as assessed by gross examination and histopathology. British Poultry Science 2005;46:394-400.

Kaya S. Yem ve besinlerdeki mikotoksinler: insan hayvan sağlığı için önemleri. Ankara Universitesi Veteriner Fakültesi Dergisi 1989;36:226253.

Kiran MM, Demet O, Ortatatli M, Oguz $\mathrm{H}$. The preventive effect of polyvinyl-polypyrrolidone on aflatoxicosis in broilers. Avian Pathology 1998:27:250-255.

Kubena LF, Harvey RB, Huff WE, Corrier DE, Phillips TD, Rottinghaus GE.Efficacy of hydrated sodium calcium aluminosilicate to reduce the toxicity of aflatoxin and t-2 toxin. Poultry Science 1990;69:1078-1086.

Luna LG. Processing of tissue. In: Luna LG. Manual of histology staining methods of the armed forces institute of pathology. 3rd ed. New York; 1968.

Magnoli AP, Monge MP, Nazar FN, Magnoli CE, Cavaglieri LR, Bagnis G, et al. Combined effects of aflatoxin B1 and corticosterone treatment on selected performance indices and liver histopathology in Japanese quail. Poultry Science 2012;91:354-361.

NRC - National Research Council. Nutrient requirements of poultry. 9th ed. Washington; 1994.

Oguz $\mathrm{H}$. The preventive efficacy of polyvinylpolypyrrolidone (PVPP) alone and its combination with the other adsorbents into broiler feeds against aflatoxicosis [dissertation]. Konya (TR): University of Selcuk; 1997.

Oguz H, Parlat SS. Effects of dietary mannanoligosaccharide on performence of japanese quail affected by aflatoxicosis. South African Journal of Animal Science 2004:34:144-148. 
Oguz $\mathrm{H}$. A review from experimental trials on detoxification of aflatoxin in poultry feed. Eurasian Journal of Veterinary Science 2011;27:1-12.

Oliveira CAF, Rosmaninho JF, Butkeraitis P, Correa B, Reis A, Guerra JL, et al. Effect of low levels of dietary aflatoxin b1 on laying japanese quail. Poultry Science 2002;81:976-980.

Ortatatli $\mathrm{M}$, Oguz $\mathrm{H}$. Ameliorative effects of dietary clinoptilolite on pathological changes in broiler chickens during aflatoxicosis. Research in Veterinary Science 2001;71:59-66.

Ortatatli M, Ciftci MK, Tuzcu M, Kaya A. The effects of aflatoxin on the reproductive system of roosters. Research in Veterinary Science 2002;72:29-36.

Ortatatli M, Oguz H, Hatipoglu F, Karaman M. Evaluation of pathological changes in broilers during chronic aflatoxin (50 and $100 \mathrm{ppb}$ ) and clinoptilolite exposure. Research in Veterinary Science 2005;78:61-68.

Parlat SS, Ozcan M, Oguz H. Biological suppresion of aflatoxicosis in japanese quail (coturnix coturnix japonica) by dietary addition of yeast (saccharomyces cerevisae). Research in Veterinary Science 2001;71:207 $-211$.

Raju MVLN, Devegowda G. Influence of esterified-glucomannan on performance and organ morphology, serum biochemistry and haematology in broilers exposed to individual and combined mycotoxicosis (aflatoxin, ochratoxin and T-2 toxin). British Poultry Science 2000;41:640-650.
Ruff MD, Huff WE, Wilkins GC. Characterization of the toxicity of the mycotoxins aflatoxin, ochratoxin, and t-2 toxin in game birds. III. bobwhite and japanese quail. Avian Diseases 1992;36:34-39.

Sawhney DS, Vadehra DV, Baker RC. Aflatoxicosis in the laying japanese quail (coturnix coturnix japonica). Poultry Science 1973;52:465-473.

Sehu A, Cakir S, Cengiz Ö, Essiz D. Mycotox $®$ and aflatoxicosis in quails. British Poultry Science 2005;46:520-524.

Shotwell OL, Hesseltine CV, Stubblefield RD, Sorenson WG. Production of aflatoxin on rice. Journal of Applied Microbiology 1966;14:425-429.

Stanley VG, Ojo R, Woldensenbet S, Hutchinson DH. The use of Saccharomyces cerevisiae, to suppress the effect of aflatoxicosis in broiler chicks. Poultry Science 1993;72:1867-1872.

Sur E, Celik I. Effects of aflatoxin b1 on the development of bursa of fabricius and blood lymphocyte acid phosphatase of the chicken. British Poultry Science 2003;44:558-566.

Valchev I, Kanakov D, Hristov TS, Lazarov L, Binev R, Grozeva N, et al. Effects of experimental aflatoxicosis on renal function in broiler chickens. Bulgarian Journal of Veterinay Medicine 2014;17:302-313. 
